\title{
A paired membrane umbrella double-lumen cannula ensures consistent cavopulmonary assistance in a Fontan sheep model
}

\author{
Dongfang Wang, MD, PhD, ${ }^{\text {a }}$ Guodong Gao, MD, ${ }^{a}$ Mark Plunkett, MD, ${ }^{a}$ Guangfeng Zhao, PhD, \\ Stephen Topaz, BS, ${ }^{b}$ Cherry Ballard-Croft, PhD, ${ }^{\text {a }}$ and Joseph B. Zwischenberger, MD ${ }^{\mathrm{a}}$
}

\begin{abstract}
Objectives: The Avalon Elite (Macquet, Rastatt, Germany) double-lumen cannula can provide effective cavopulmonary assistance in a Fontan (total cavopulmonary connection) sheep model, but it requires strict alignment. The objective was to fabricate and test a newly designed paired umbrella double-lumen cannula without alignment requirement.
\end{abstract}

\begin{abstract}
Methods: The paired membrane umbrellas were designed on the double-lumen cannula to bracket infusion blood flow toward the pulmonary artery. Two umbrellas were attached, one $4 \mathrm{~cm}$ above and one $4 \mathrm{~cm}$ below the infusion opening. Umbrellas were temporarily wrapped and glued to the double-lumen cannula body to facilitate insertion. A total cavopulmonary connection mock loop was used to test cavopulmonary assistance performance and reliability with double-lumen cannula rotation and displacement. The paired umbrella double-lumen cannula also was tested in a total cavopulmonary connection adult sheep model $(\mathrm{n}=6)$.
\end{abstract}

Results: The bench test showed up to $4.5 \mathrm{~L} / \mathrm{min}$ pumping flow and approximately $90 \%$ pumping flow efficiency at $360^{\circ}$ rotation and $8-\mathrm{cm}$ displacement of double-lumen cannula. The total cavopulmonary connection model with compromised hemodynamics was successfully created in all 6 sheep. The cavopulmonary assistance double-lumen cannula with paired umbrellas was smoothly inserted into the superior vena cava and extracardiac conduit in all sheep. At 3.5 to $4.0 \mathrm{~L} / \mathrm{min}$ pump flow, the systolic arterial blood pressure and central venous pressure returned to normal baseline and remained stable throughout the 90-minute experiment, demonstrating effective cavopulmonary assistance support. Double-lumen cannula rotation and displacement did not affect performance. Autopsy revealed well-opened and positioned paired umbrellas, and double-lumen cannulas were easily removed from the right jugular vein.

Conclusions: Our double-lumen cannula with paired umbrellas is easy to insert and remove. The paired umbrellas eliminated the strict alignment requirement and ensured consistent cavopulmonary assistance performance. (J Thorac Cardiovasc Surg 2014;148:1041-7)

The Fontan or total cavopulmonary connection (TCPC) procedure has been used to palliate the univentricular heart for more than 40 years. $^{1}$ After decades of modification and improvement, TCPC provides excellent short-term outcome with less than $2 \%$ early mortality. ${ }^{2,3}$ However, long-term outcome is poor with as high as $30 \%$ mortality at 25 years after the procedure. ${ }^{4,5}$ Fontan patients exhibit hypercoagulability due to venous stasis along with an imbalance in procoagulant and anticoagulant factors,

\footnotetext{
From the Cardiothoracic Surgery Division, ${ }^{a}$ Department of Surgery, University of

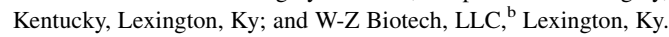

Funded by National Institutes of Health Grant 1R41HL107062-01A1 and Johnston-Wright Endowment, University of Kentucky Department of Surgery.

Disclosures: Dongfang Wang and Joseph B. Zwischenberger report equity ownership in W-Z Biotech, LLC. All other authors have nothing to disclose with regard to commercial support.

Read at the 94th Annual Meeting of The American Association for Thoracic Surgery, Toronto, Ontario, Canada, April 26-30, 2014.

Received for publication March 12, 2014; revisions received March 25, 2014; accepted for publication April 2, 2014; available ahead of print June 13, 2014

Address for reprints: Dongfang Wang, MD, PhD, Department of Surgery, University of Kentucky College of Medicine, 800 Rose St, MN269, Lexington, KY 40536-0298 (E-mail: dnwang2@email.uky.edu).

$0022-5223 / \$ 36.00$

Copyright (c) 2014 by The American Association for Thoracic Surgery

http://dx.doi.org/10.1016/j.jtcvs.2014.04.051
}

resulting in chronic pulmonary embolism. ${ }^{6,7}$ The combination of pulmonary embolism and systemic to pulmonary collateral formation ${ }^{8}$ increases pulmonary vascular resistance and elevates central venous pressure (CVP) to an undesired level. This causes low cardiac output, peripheral tissue fluid accumulation (edema), proteinlosing enteropathies, pleural effusions, ascites, and systemic congestion, compromising systemic/pulmonary organ function. A cavopulmonary assistance (CPA) device is needed to actively move blood from the superior vena cava (SVC)/inferior vena cava (IVC) through the TCPC connection to the pulmonary artery (PA), decreasing CVP, increasing cardiac output, and reversing pathophysiology of the failing Fontan circulation.

Our patented Avalon Elite (Macquet, Rastatt, Germany) double-lumen cannula (DLC) can fit in the Fontan anastomosis in a special TCPC sheep model ${ }^{9}$ through percutaneous right jugular vein (RJV) cannulation, providing effective CPA. However, this CPA system is not clinically practical because of the (1) requirement of strict DLC outlet alignment to single pulmonary anastomosis to prevent significant recirculation and (2) perfusion of only 1 lung. ${ }^{10}$ 


$$
\begin{aligned}
& \text { Abbreviations and Acronyms } \\
& \text { CPA = cavopulmonary assistance } \\
& \text { CVP = central venous pressure } \\
& \text { DLC }=\text { double-lumen cannula } \\
& \text { ECC }=\text { extracardiac conduit } \\
& \text { IVC }=\text { inferior vena cava } \\
& \text { LPA = left pulmonary artery } \\
& \text { PA }=\text { pulmonary artery } \\
& \text { RA }=\text { right atrium } \\
& \text { RJV = right jugular vein } \\
& \text { RPA }=\text { right pulmonary artery } \\
& \text { SABP }=\text { systolic arterial blood pressure } \\
& \text { SVC = superior vena cava } \\
& \text { TCPC = total cavopulmonary connection } \\
& \text { VAD = ventricular assist device }
\end{aligned}
$$

We modified the Avalon Elite DLC by adding a pair of membrane umbrellas on both sides of the infusion outlet of DLC. These paired umbrellas generate a higher pressure zone and prevent recirculation, eliminating the requirement of strict DLC alignment and perfusing both lungs. We tested the feasibility and CPA performance of this CPA DLC in both a mock loop simulation and a TCPC sheep model.

\section{METHODS \\ Paired Membrane Umbrella Cavopulmonary Assist Double-Lumen Cannula Design}

The paired membrane umbrella CPA DLC is based on our patented Avalon Elite DLC, which is inserted from the RJV into the SVC-Fontan anastomoses-IVC. One drainage lumen has 2 openings for blood drainage from both the SVC and the IVC. The infusion lumen outlet is located between the 2 drainage openings for blood delivery to pulmonary arteries. Each membrane umbrella is positioned between the infusion opening and the drainage opening, with one umbrella above and one umbrella below the infusion opening (Figure 1, A).

The paired membrane umbrellas are directional. They block backward blood flow from the infusion opening to the drainage openings, eliminating recirculation. The paired membrane umbrellas are safe in terms of CPA system failure events. When the CPA system malfunctions, the paired membrane umbrellas close to allow blood flow from the SVC/IVC to the PA as unassisted TCPC (Figure 1,B).

\section{How the Paired Membrane Umbrella Cavopulmonary Assist Double-Lumen Cannula Works}

The paired membrane umbrellas were wrapped and temporarily glued to the DLC with saturated dextrose, facilitating percutaneous insertion (Figure 2). The dextrose is easily dissolved in blood after the CPA DLC is positioned inside the SVC/IVC. When the pump initiates, the venous blood in SVC/IVC is withdrawn, generating lower pressure beyond the paired membrane umbrellas, and blood from the pump is delivered into the area between the paired membrane umbrellas, generating higher pressure and perfusing both the left pulmonary artery (LPA) and the right pulmonary artery (RPA). This pressure gradient across the paired umbrellas expends/deploys the membrane umbrellas, preventing blood recirculation from the PA (within the membrane umbrella) to the DLC drainage opening in the SVC/IVC (beyond the paired membrane umbrellas). Therefore, there is a higher pressure zone between the paired membrane umbrellas to perfuse the PA. As long as the Fontan anastomoses are within this zone, the CPA system will work well. DLC rotation/disorientation does not affect CPA performance. This design eliminates the strict alignment requirement, allowing limited patient ambulation.

\section{Fabrication}

The membrane umbrellas were made by dip molding polyurethane with a thickness of $0.15 \mathrm{~mm}$. The outer diameter of the umbrella edge was 2.0 $\mathrm{cm}$. The paired membrane umbrella was attached to a $27 \mathrm{~F}$ commercial Avalon Elite DLC (Figure 2, $A$ and $B$ ). The 4-0 Ethicon sutures were used to secure umbrellas, preventing umbrella reversal under pressure. The distance between the umbrellas was $8 \mathrm{~cm}$.

\section{Bench Test}

The bench test was performed in a Fontan simulation loop. A polycarbonate tube (internal diameter $20 \mathrm{~mm}$ ) was used to mimic the SVC and IVC; both were connected to a venous reservoir. Two polyvinyl chloride tubes (internal diameter of $9.5 \mathrm{~mm}$ ) were perpendicularly attached to polycarbonate tubing to mimic the LPA and RPA in TCPC and connected to a pulmonary reservoir. The bench circuit was filled with $37 \%$ glycerin to mimic blood viscosity. The CPA DLC with the paired umbrella was placed from the SVC into the IVC and connected to a CentriMag pump (Thoratec Corp, Pleasanton, Calif). When the pump started, fluid was withdrawn from both the SVC and IVC outside the umbrellas and perfused between the umbrellas, generating a pressure gradient across membrane umbrellas. This pressure gradient deployed (opened) the membrane umbrellas. During the bench testing, the pumping flow was set from 1.0 to $4.5 \mathrm{~L} / \mathrm{min}$. The fluid levels of the venous reservoir were adjusted to $13.6 \mathrm{~cm}$ above the DLC to mimic $10 \mathrm{~mm} \mathrm{Hg} \mathrm{CVP}$, and the fluid levels of the pulmonary reservoir were adjusted to $34 \mathrm{~cm}$ above the DLC to mimic $25 \mathrm{~mm} \mathrm{Hg}$ PA pressure. Therefore, fluid was pumped from the low-pressure venous reservoir to the high-pressure pulmonary reservoir through the CPA DLC. Three flow sensors were placed on the RPA, LPA, and CPA DLC infusion cannula tubing.

To test whether CPA DLC rotation and displacement affect CPA performance, flow efficiencies were measured/calculated when the cannula was rotated 180 degrees or moved up/down $4 \mathrm{~cm}$. The flow efficiency was calculated as the percentage of total flow through the LPA and RPA compared with total pumping flow through the DLC infusion lumen.

\section{In Vivo Test in Failing Fontan Circulation Sheep Model}

All animal studies were approved by the University of Kentucky Institutional Animal Care and Use Committee and conducted in accordance with the Principles of Laboratory Animal Care (National Society of Medical Research) and the "Guide for the Care and Use of Laboratory Animals" (National Institutes of Health publication no. 85-23, revised 1996). Six adult female cross-bred sheep (35-45 kg) were used in this study.

\section{Animal Preparation, Instrumentation, and Surgical Procedure}

After induction with ketamine ( $5 \mathrm{mg} / \mathrm{kg}$, intravenously) and diazepam $(0.25 \mathrm{mg} / \mathrm{kg}$, intravenously), all sheep were intubated and connected to the anesthesia machine (Narkomed 2B, DRAGER, Telford, Pa). Anesthesia was maintained with $1 \%$ to $3 \%$ isoflurane, titrating a normal range of heart rate and arterial blood pressure. Arterial/venous catheters (BD Medical Inc, Sandy, Utah) were placed into the right femoral artery/vein to monitor pressure and administer fluid. 


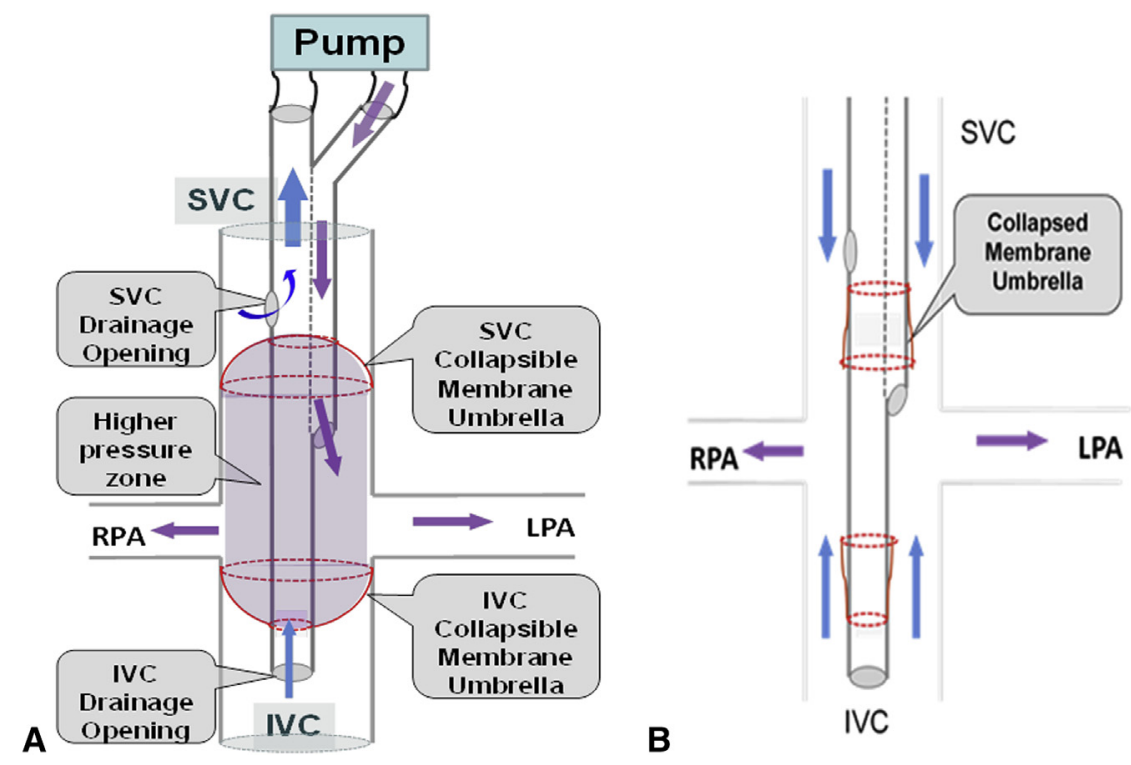

FIGURE 1. The CPA DLC design with paired membrane umbrellas. A, The paired membrane umbrellas CPA DLC inside the Fontan anastomosis. Drainage lumen has 2 openings for blood drainage from the SVC and IVC. The infusion lumen outlet is between the 2 drainage openings for blood delivery to the RPA/LPA. Each membrane umbrella is positioned between the infusion opening and the drainage opening, with 1 umbrella above and 1 umbrella below the infusion opening. The drainage lumen withdraws blood from the SVC and IVC, and the infusion lumen delivers blood to the area between the umbrellas. The pressure gradient between the infusion and drainage openings opens the umbrellas. The opened umbrellas block infusion blood backflow to the drainage opening, preventing recirculation. B, Safety of paired membrane umbrellas. When the CPA system malfunctions, the paired membrane umbrellas close to allow blood flow from the SVC/IVC to the PA as unassisted TCPC, preventing immediate patient death from circulatory collapse. $I V C$, Inferior vena cava; $R P A$, right pulmonary artery; $S V C$, superior vena cava; $L P A$, left pulmonary artery.

A right lateral thoracotomy was performed through the fourth intercostal space. The pericardium was opened to expose the SVC, IVC, and right atrium (RA). The SVC was isolated. Purse strings were placed on the SVC and RA. A bolus of heparin $(150 \mathrm{U} / \mathrm{kg})$ was administered intravenously, and the activated clotting time was maintained at range of 200 to 300 seconds with supplemental dosage. Two cannulae (24F) were placed into the SVC and RA appendage through the purse strings and connected by a 3/8" Tygon tubing (Saint Gobain Corporation, Akron, Ohio) to create an SVC-RA bypass. Two clamps were applied on the SVC between the SVC cannula and the RA, and the SVC was cut between these 2 clamps. The blood from the SVC flowed into the RA through the SVC-RA bypass, maintaining stable circulation without the need for cardiopulmonary bypass. The RA cut end was closed by a continuous running suture, and the clamp on the RA side was removed. Both SVC cut ends were pulled away for better exposure and full isolation of RPA. A side-biter clamp was placed on the RPA, and a 2-cm incision was made on the RPA for anastomosis. An extracardiac conduit (ECC) $(18 \mathrm{~mm})$ (polytetrafluoroethylene; Gore-Tex, WL Gore \& Associates Inc, Flagstaff, Ariz) was anastomosed to the RPA in a side-to-side fashion. The SVC cut end was anastomosed to the ECC in an end-to-end fashion. The same temporary bridge was created between the IVC and the RA, allowing the IVC to be cut off from the RA. The RA cut end was closed by a continuous running suture. The IVC cut end was anastomosed to the other end of the ECC in an end-to-end fashion. After clamping and removing the 2 temporary SVC/ IVC-RA bypasses, total SVC/IVC blood flow was completely diverted into the pulmonary circulation.

The CPA DLC was inserted from a cut on the RJV, advanced into the SVC Fontan anastomosis ECC, and connected to the primed pump circuit. The CentriMag pump was started, and pump flow was gradually increased to achieve a systolic arterial blood pressure (sABP) greater than $90 \mathrm{~mm} \mathrm{Hg}$.

\section{Data Collection and Analysis}

The femoral arterial/venous catheters were connected to transducers (Edwards Lifesciences, Irvine, Calif) for pressure monitoring. Arterial blood pressure and CVP were continuously monitored during surgery via a Philips MP-50 monitor (Philips Medical Systems, Boeblingen, Germany). The sABP, CVP, and heart rate were recorded at the time points of normal baseline, TCPC, and TCPC with CPA. All data were expressed as mean \pm standard error. Differences between the time points were evaluated using the Student $t$ test.

\section{Necropsy}

After the experiment was finished, all sheep were euthanized with Beuthanasia-D (1 mL/10 lb) (Schering-Plough, Union, NJ). The RPA anastomosis, bridge graft, CPA DLC position, and potential thrombosis were visualized at necropsy.

\section{RESULTS \\ Bench Test}

In the pressure-flow test, the CPA DLC could handle up to $4.5 \mathrm{~L} / \mathrm{min}$ blood flow (Figure 3). With a flow of $4.0 \mathrm{~L} / \mathrm{min}$, the drainage pressure was $-102 \mathrm{~mm} \mathrm{Hg}$ and infusion pressure was $260 \mathrm{~mm} \mathrm{Hg}$. Position-dependent CPA performance was tested by measuring CPA efficiency with DLC rotation or displacement. The flow efficiency was approximately $90 \%$ with $360^{\circ}$ rotation. The flow efficiency was approximately $90 \%$ with $8-\mathrm{cm}$ cannula displacement $(4 \mathrm{~cm}$ up and $4 \mathrm{~cm}$ down). This demonstrated that flow efficiency was dependable as the cannula was rotated and displaced.

\section{In Vivo Test}

The TCPC model was successfully created in all 6 sheep. After all the anastomoses were completed and the 

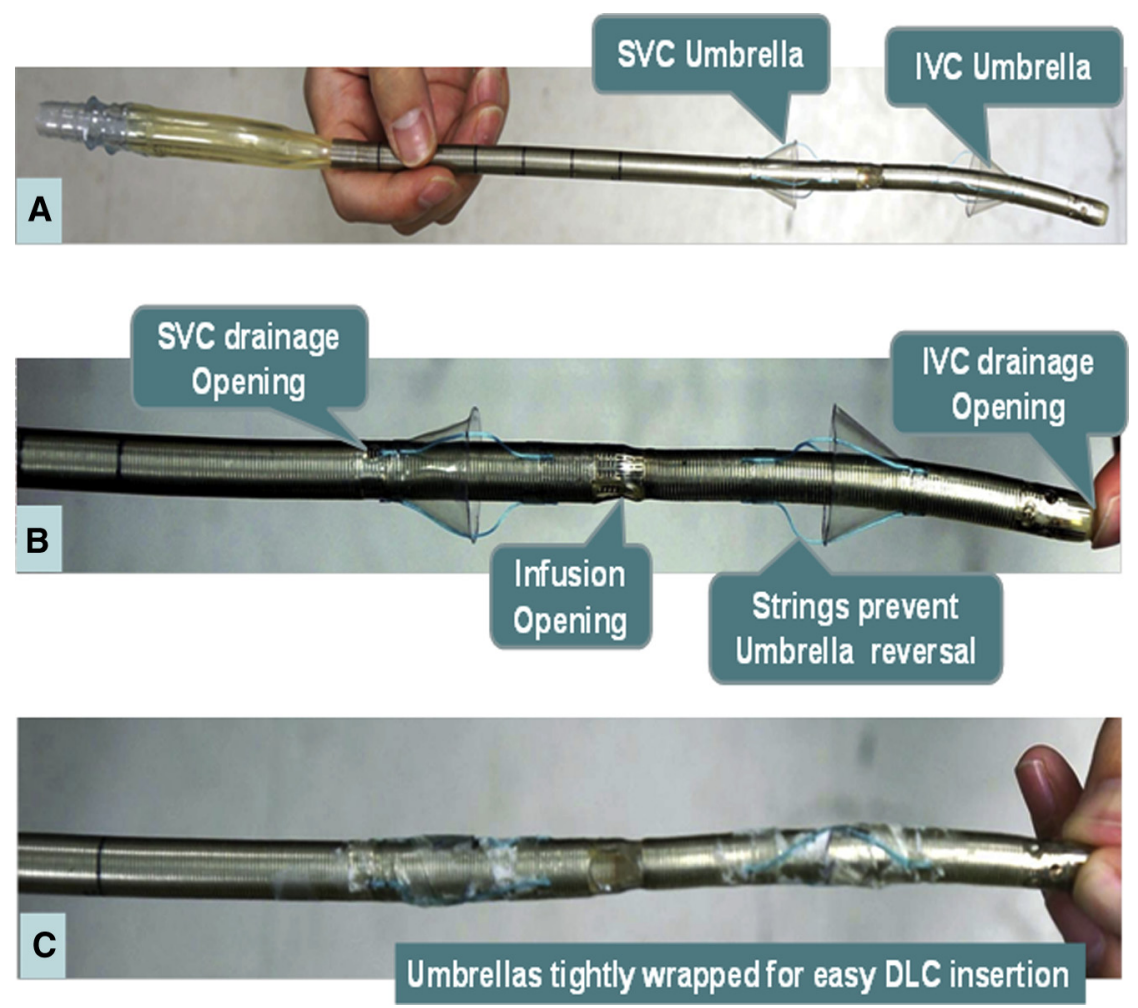

FIGURE 2. Paired membrane CPA DLC prototype. A, Overall view of the prototype. B, The drainage lumen opening beyond the paired membrane umbrellas and infusion lumen opening between the paired membrane umbrellas. C, The paired membrane umbrellas were tightly wrapped and temporarily glued to the DLC with saturated dextrose for easy DLC insertion. DLC, Double-lumen cannula; $I V C$, inferior vena cava; $S V C$, superior vena cava.

SVC/IVC-RA bypasses were removed, the venous blood from the SVC and IVC was completely diverted to the PA, bypassing the right ventricle. The CVP was significantly elevated from $5 \pm 0.8 \mathrm{~mm} \mathrm{Hg}$ to $17 \pm 2.2 \mathrm{~mm} \mathrm{Hg}(P<.01)$, and sABP was significantly decreased from $97 \pm 3.3 \mathrm{~mm} \mathrm{Hg}$ to $45 \pm 4.3 \mathrm{~mm} \mathrm{Hg}$ $(P<.01)$, demonstrating failing Fontan circulation.

The CPA DLCs with folded/glued membrane umbrellas were successfully inserted from the RJV and advanced to TCPC anastomoses in all 6 sheep on the first attempt. After connection to a CentriMag pump, the pumping flow was adjusted to 3.5 to $4.5 \mathrm{~L} / \mathrm{min}$ until CVP and sABP returned to baseline values. The CVP was $8 \pm 1.4 \mathrm{~mm} \mathrm{Hg}$ and sABP was $92 \pm 4.5 \mathrm{~mm} \mathrm{Hg}$ at 10 minutes of CPA $(P>.05$ compared with baseline) (Table 1). At 15 minutes, the CPA circuit was clamped and the pump was turned off. The CVP increased to $13 \pm 2.5 \mathrm{~mm} \mathrm{Hg}$, and sABP decreased to $52 \pm 12.9 \mathrm{~mm} \mathrm{Hg}$ (Table 1). This indicated that the correction of failing Fontan circulation was solely attributed to the CPA system and that the paired membrane umbrellas closed during CPA malfunction to allow blood flow from the SVC/IVC to the PA as an unassisted TCPC without blockage. When the pump was turned back on, the CVP and SABP were maintained at baseline values throughout the rest of the experiment. Heart rate had no significant change throughout the experiment. Before experiment termination, the CPA DLCs were easily taken out of the RJV.

\section{Necropsy}

No tearing due to CPA DLC withdrawal was observed in the RJV. All of the TCPC anastomoses were intact.

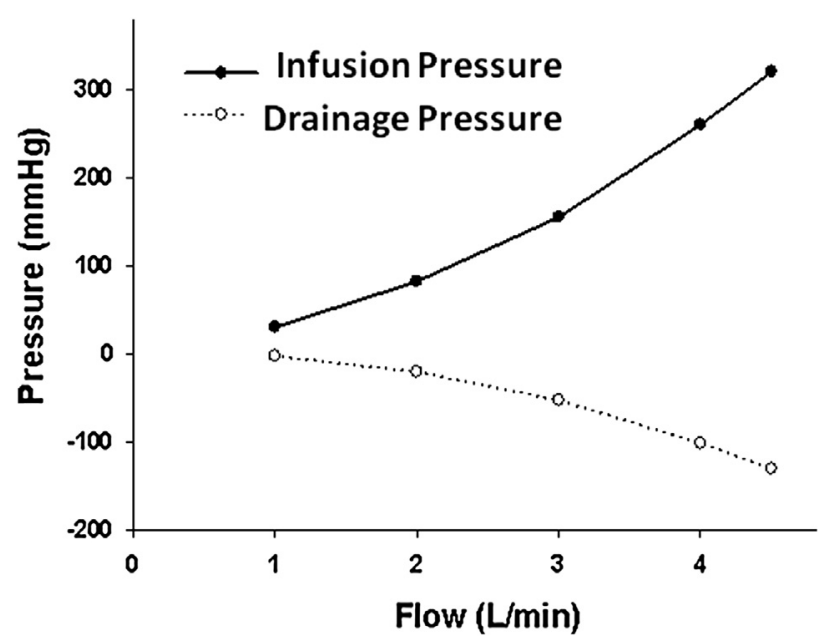

FIGURE 3. The CPA DLC prototype performance. The pressure-flow chart shows that the CPA DLC can handle up to $4.5 \mathrm{~L} / \mathrm{min}$ blood flow. 
TABLE 1. Hemodynamic changes in sheep study

\begin{tabular}{|c|c|c|c|c|c|c|c|}
\hline & Baseline & TCPC & $\begin{array}{c}\text { CPA } \\
10 \mathrm{~min} \\
\end{array}$ & $\begin{array}{c}\text { CPA } \\
\text { Pump off }\end{array}$ & $\begin{array}{c}\text { CPA } \\
30 \mathrm{~min}\end{array}$ & $\begin{array}{c}\text { CPA } \\
60 \mathrm{~min} \\
\end{array}$ & $\begin{array}{c}\text { CPA } \\
90 \mathrm{~min} \\
\end{array}$ \\
\hline sABP (mm Hg) & $97 \pm 3.3$ & $45 \pm 4.3^{*}$ & $92 \pm 4.5$ & $52 \pm 12.9^{*}$ & $100 \pm 4.0$ & $97 \pm 0.6$ & $96 \pm 7.0$ \\
\hline $\mathrm{CVP}(\mathrm{mm} \mathrm{Hg})$ & $5.0 \pm 0.8$ & $17.0 \pm 2.2 \dagger$ & $8.3 \pm 1.4$ & $13.0 \pm 2.5^{*}$ & $7.0 \pm 1.4$ & $7.7 \pm 1.2$ & $7.0 \pm 2.1$ \\
\hline HR (beats/min) & $109 \pm 10$ & $104 \pm 16$ & $106 \pm 16$ & $100 \pm 36$ & $111 \pm 12$ & $115 \pm 20$ & $117 \pm 21$ \\
\hline
\end{tabular}

After the TCPC procedure, there was a significant decrease in sABP and a significant increase in CVP. During 90 minutes of CPA, sABP increased and CVP decreased to baseline levels. When the DLC was clamped at 15 minutes of CPA to mimic pump failure/DLC kinking, sAPB decreased and CVP increased to unassisted TCPC levels, but did not cause circulatory collapse, indicating that the closed umbrellas did not obstruct blood flow from the SVC/IVC to the PA. CPA, Cavopulmonary assistance; $C V P$, central venous pressure; $H R$, heart rate; $s A B P$, systolic arterial blood pressure; $T C P C$, total cavopulmonary connection. $* P<.05$ versus baseline. $\dagger P<.001$ versus baseline.

No thrombosis was observed inside the SVC, IVC, RPA, and ECC around the TCPC anastomosis. The CPA DLC umbrella was opened, and a small amount of thrombosis was observed under the umbrella.

\section{DISCUSSION}

We showed that our percutaneous DLC-based CPA system provided effective cavopulmonary support in a TCPC sheep model. This study also showed the practicality and efficiency of our new DLC-based CPA system: (1) The CPA DLC with folded membrane umbrellas was easily inserted from the RJV and advanced to the TCPC anastomoses; (2) the folded umbrellas opened and blocked backward flow for minimal recirculation $(<10 \%)$ from the PA to the SVC/IVC; (3) the CPA DLC rotation or displacement within $8 \mathrm{~cm}$ did not affect CPA performance; and (4) when the CPA pump stopped, the CPA paired membrane umbrellas closed to allow the blood flow from the SVC/IVC toward pulmonary anastomosis.

\section{Fontan Pathophysiology}

The Fontan procedure separates the pulmonary and systemic circulations to correct cyanosis. However, the Fontan circulation is not a normal circulation because there is no pump to push blood through the pulmonary system. The patient's exercise capacity progressively declines after the Fontan procedure. ${ }^{5}$ Fontan patients exhibit hypercoagulability due to venous stasis and imbalance of procoagulant and anticoagulant factors, resulting in chronic pulmonary embolism. ${ }^{6,7}$ The combination of pulmonary embolism and systemic to pulmonary collateral formation ${ }^{8}$ increases pulmonary vascular resistance. Increased pulmonary vascular resistance triggers a vicious cascade of failing Fontan pathophysiology, affecting both the venous and arterial sides. On the venous side, increased pulmonary vascular resistance requires further CVP increases to compensate for inadequate pulmonary blood flow and cardiac output. Elevated CVP backs up venous blood flow, increasing capillary blood pressure and capillary leak, and promoting lymphatic fluid production. Elevated CVP also backs up the lymphatic system, blocking lymphatic fluid return to circulation. Ultimately, elevated CVP causes end-organ venous congestion, increased peripheral tissue fluid (edema), protein-losing enteropathies, pleural effusions, and ascites. On the arterial side, increased pulmonary vascular resistance decreases pulmonary blood flow, reducing preload to the single ventricle and cardiac output. Furthermore, low pulmonary blood flow results in inadequate oxygenation. Low blood perfusion in the arterial side and high blood congestion in the venous side impair end organs (eg, liver, kidneys, heart). As the failing Fontan circulation enters the decompensation stage, the patient's physical condition and end-organ function progressively deteriorate, which often results in their removal from the heart transplant waiting list or higher post-transplant morbidity. ${ }^{11}$

\section{Requirement of Cavopulmonary Assist}

For patients with failing Fontan circulation, CPA is highly desired to pump venous blood from both the SVC/IVC to the PA through the Fontan connection. CPA lowers CVP, promoting venous/lymphatic return and decreasing lymphatic fluid generation. This decreases fluid accumulation in the tissue and body cavity, eliminating edema, protein-losing enteropathies, pleural effusions, ascites, and end-organ venous congestion. CPA pumps more blood through the pulmonary circulation and increases cardiac output, improving end-organ perfusion and oxygenation. Therefore, CPA may restore compromised end-organ function and improve the general physical condition of patients. For very sick patients who are not eligible for heart transplant, CPA can potentially rehabilitate them to become good candidates for heart transplantation. Furthermore, CPA may smooth post-transplant recovery and decrease post-transplant morbidity.

\section{Two Currently Available Technologies for}

Cavopulmonary Assist Device: Ventricular Assist

Extracorporeal Membrane Oxygenation and

\section{Regular Ventricular Assist Device}

The VA ECMO is used to assist the patient with failing Fontan circulation. ${ }^{12-14}$ However, ECMO is timelimited, labor-intensive, and expensive. The bulky ECMO system includes an oxygenator, a complex circuit, and full anticoagulation. ECMO also is nonambulatory and 
associated with a high morbidity and mortality. ${ }^{15}$ A regular ventricular assist device (VAD) could be used for CPA application, but it is challenged by the Fontan anatomy. In the Fontan procedure, the SVC and IVC are individually connected to the RPA without a reservoir/chamber for the VAD drainage cannula. The PA cannot be used for VAD blood infusion because the infusion blood will flow back to the IVC/SVC, resulting in serious recirculation. To use a regular VAD for CPA, the Fontan must be taken down and the SVC and IVC connected to create a compliance chamber for VAD drainage. This high-risk procedure is complicated, requiring cardiopulmonary bypass support. ${ }^{16}$

\section{Emerging Technology}

To achieve CPA, venous blood has to be moved from both the SVC and the IVC to the PA. It is challenging to move blood from opposite directions (SVC and IVC) to the PA. Two types of catheter pumps are under development for CPA. An axial flow catheter pump, such as the Hemopump (Johnson and Johnson Interventional Systems, Rancho Cordova, Calif), could be used for CPA. ${ }^{17-30}$ The axial flow blood pump can only pump blood to the PA from 1 direction, from the SVC or the IVC. To pump total venous blood from both the SVC and the IVC to the PA, 2 individual axial flow blood pumps are required, one cannulated from the RJV to pump blood from the SVC and one cannulated from the right femoral vein to pump blood from the IVC. It cannot be ambulatory because of femoral vein cannulation. The centrifugal force catheter pump with folding blades and novel von Karman viscous impeller pump (Jabsco, Costa Mesa, Calif) also were developed for CPA. ${ }^{18,30-33}$ However, centrifugal force catheter pumps require strict alignment with the PA.

We have applied our patented Avalon Elite DLC in a failing Fontan sheep model, providing effective CPA. Like all other catheter-mounted centrifugal force pumps, the CPA performance was completely dependent on strict outlet alignment to single pulmonary anastomosis to prevent significant recirculation. ${ }^{10}$ The requirement of precise alignment with the PA is not clinically practical because any slight patient movement will adversely affect this alignment, compromising CPA performance. Even in deeply sedated patients, any passive movement from daily nursing will impair the precise alignment and CPA performance. Another major disadvantage is that the Avalon Elite DLC-based CPA system perfuses only 2 lungs.

To solve these problems, we redesigned the CPA DLC to allow its rotation/dislocation and limited patient movability without compromising CPA performance. The paired membrane umbrellas bracket the infusion opening, preventing infusion blood recirculation. Now, the PA is required to be aligned only within the zone between the paired umbrellas, generously allowing up to $8 \mathrm{~cm}$ of DLC dislodgement from the patient's movement. This
DLC-based CPA system generates a higher pressure zone between the paired membrane umbrellas, guaranteeing the perfusion of both lungs. Rotation of the DLC does not affect CPA performance.

The design of the paired membrane umbrellas was chosen to ensure patient safety in the event of CPA circuit failure. When the CPA circuit fails (pump stopping or circuit kinking), the paired membrane umbrellas close to allow unobstructed blood flow from the SVC/IVC toward the PA like an unassisted failing Fontan circulation. In this scenario, an inflated balloon would completely block blood flow to the PA, causing immediate circulatory collapse and patient death.

\section{Study Limitations}

In the current design, blood stagnancy exists around the umbrellas, resulting in thrombosis. The CPA DLC must be redesigned for an even flow pattern to eliminate potential thrombosis.

\section{CONCLUSIONS}

Our DLC with paired umbrellas is easy to insert and remove. The paired umbrellas eliminated the strict alignment requirement and ensured consistent CPA performance. Our DLC-based CPA device is a practical and efficient way to achieve effective CPA.

\section{References}

1. Fontan F, Baudet E. Surgical repair of tricuspid atresia. Thorax. 1971;26:240-8.

2. d'Udekem Y, Iyengar AJ, Cochrane AD, Grigg LE, Ramsay JM, Wheaton GR, et al. The Fontan procedure: contemporary techniques have improved longterm outcomes. Circulation. 2007;116:1157-64.

3. Tweddell JS, Nersesian M, Mussatto KA, Nugent M, Simpson P, Mitchell ME, et al. Fontan palliation in the modern era: factors impacting mortality and morbidity. Ann Thorac Surg. 2009;88:1291-9.

4. Khairy P, Fernandes SM, Mayer JE Jr, Triedman JK, Walsh EP, Lock JE, et al. Long-term survival, modes of death, and predictors of mortality in patients with Fontan surgery. Circulation. 2008;117:85-92.

5. Giardini A, Hager A, Pace Napoleone C, Picchio FM. Natural history of exercise capacity after the Fontan operation: a longitudinal study. Ann Thorac Surg. 2008; $85: 818-21$.

6. Odegard KC, McGowan FX Jr, Zurakowski D, Dinardo JA, Castro RA, delNido PJ, et al. Procoagulant and anticoagulant factor abnormalities following the Fontan procedure: increased factor VIII may predispose to thrombosis. J Thorac Cardiovasc Surg. 2003;125:1260-7.

7. Odegard KC, Zurakowski D, DiNardo JA, Castro RA, McGowan FX Jr, Neufeld EJ, et al. Prospective longitudinal study of coagulation profiles in children with hypoplastic left heart syndrome from stage I through Fontan completion. J Thorac Cardiovasc Surg. 2009;137:934-41.

8. Ascuitto RJ, Ross-Ascuitto NT. Systematic-to-pulmonary collaterals: a source of flow energy loss in Fontan physiology. Pediatr Cardiol. 2004;25:472-81.

9. Wang D, Plunkett M, Gao G, Zhou X, Ballard-Croft C, Reda H, et al. A practical and less invasive total cavopulmonary connection sheep model. ASAIO J. 2014; 60:178-82.

10. Wang D, Plunkett M, Lynch J, Zhou X, Ballard-Croft C, Zwischenberger JB. Wang-Zwische double-lumen cannula leads to total cavopulmonary support in a failing Fontan sheep model. Ann Thorac Surg. 2011;91:1956-60.

11. Bernstein D, Naftel D, Chin C, Addonizio LJ, Gamberg P, Blume ED, et al. Outcome of listing for cardiac transplantation for failed Fontan: a multiinstitutional study. Circulation. 2006;114:273-80. 
12. Rogers AJ, Trento A, Siewers RD, Griffith BP, Hardesty RL, Pahl E, et al. Extracorporeal membrane oxygenation for postcardiotomy cardiogenic shock in children. Ann Thorac Surg. 1989;47:903-6.

13. Salvin JW, Scheurer MA, Laussen PC, Mayer JE Jr, Del Nido PJ, Pigula FA, et al. Factors associated with prolonged recovery after the Fontan operation. Circulation. 2008;118:S171-6.

14. Booth KL, Roth SJ, Thiagarajan RR, Almodovar MC, del Nido PJ, Laussen PC. Extracorporeal membrane oxygenation support of the Fontan and bidirectional Glenn circulations. Ann Thorac Surg. 2004;77:1341-8.

15. Chaudhari M, Sturman J, O'Sullivan J, Smith J, Wrightson N, Parry G, et al. Rescue cardiac transplantation for early failure of the Fontan-type circulation in children. J Thorac Cardiovasc Surg. 2005;129:416-22.

16. Pretre R, Haussler A, Bettex D, Genoni M. Right-sided univentricular cardiac assistance in a failing Fontan circulation. Ann Thorac Surg. 2008;86:1018-20.

17. Rodefeld MD, Boyd JH, Myers CD, LaLone BJ, Bezruczko AJ, Potter AW, et al. Cavopulmonary assist: circulatory support for the univentricular Fontan circulation. Ann Thorac Surg. 2003;76:1911-6.

18. Throckmorton AL, Kapadia J, Madduri D. Mechanical axial flow blood pump to support cavopulmonary circulation. Int J Artif Organs. 2008;31:970-82.

19. Bhavsar SS, Kapadia JY, Chopski SG, Throckmorton AL. Intravascular mechanical cavopulmonary assistance for patients with failing Fontan physiology. Artif Organs. 2009;33:977-87.

20. Throckmorton AL, Kishore RA. Design of a protective cage for an intravascular axial flow blood pump to mechanically assist the failing Fontan. Artif Organs. 2009;33:611-21.

21. Bhavsar SS, Moskowitz WB, Throckmorton AL. Interaction of an idealized cavopulmonary circulation with mechanical circulatory assist using an intravascular rotary blood pump. Artif Organs. 2010;34:816-27.

22. Kapadia JY, Pierce KC, Poupore AK, Throckmorton AL. Hydraulic testing of intravascular axial flow blood pump designs with a protective cage of filaments for mechanical cavopulmonary assist. ADSIO J. 2010;56:17-23.

23. Throckmorton AL, Kapadia JY, Wittenschlaeger TM, Medina TJ, Hoang HQ, Bhavsar SS. Filament support spindle for an intravascular cavopulmonary assist device. Artif Organs. 2010;34:1039-44.

24. Chopski SG, Downs E, Haggerty CM, Yoganathan AP, Throckmorton AL. Laser flow measurements in an idealized total cavopulmonary connection with mechanical circulatory assistance. Artif Organs. 2011;35:1052-64.

25. Throckmorton AL, Carr JP, Tahir SA, Tate R, Downs EA, Bhavasar SS, et al. Mechanical cavopulmonary assistance of a patient-specific Fontan physiology: numerical simulations, lumped parameter modeling, and suction experiments. Artif Organs. 2011;35:1036-47.

26. Throckmorton AL, Kapadia JY, Chopski SG, Bhavsar SS, Moskowitz WB, Gullquist SD, et al. Numerical, hydraulic, and hemolytic evaluation of an intravascular axial flow blood pump to mechanically support Fontan patients. Ann Biomed Eng. 2011;39:324-36.

27. Downs EA, Moskowitz WB, Throckmorton AL. Steady flow analysis of mechanical cavopulmonary assistance in MRI-derived patient-specific Fontan configurations. Artif Organs. 2012;36:972-80.

28. Throckmorton AL, Downs EA, Hazelwood JA, Monroe JO, Chopski SG. Twisted cardiovascular cages for intravascular axial flow blood pumps to support the Fontan physiology. Int J Artif Organs. 2012;35:369-75.
29. Throckmorton AL, Lopez-Isaza S, Downs EA, Chopski SG, Gangemi JJ, Moskowitz W. A viable therapeutic option: mechanical circulatory support of the failing Fontan physiology. Pediatr Cardiol. 2013;34:1357-65.

30. Throckmorton AL, Ballman KK, Myers CD, Frankel SH, Brown JW, Rodefeld MD. Performance of a 3-bladed propeller pump to provide cavopulmonary assist in the failing Fontan circulation. Ann Thorac Surg. 2008; 86:1343-7.

31. Rodefeld MD, Coats B, Fisher T, Giridharan GA, Chen J, Brown JW, et al Cavopulmonary assist for the univentricular Fontan circulation: von Karman viscous impeller pump. J Thorac Cardiovasc Surg. 2010;140:529-36.

32. Delorme Y, Anupindi K, Kerlo AE, Shetty D, Rodefeld M, Chen J, et al Large eddy simulation of powered Fontan hemodynamics. J Biomech. 2013; 46:408-22.

33. Giridharan GA, Koenig SC, Kennington J, Sobieski MA, Chen J, Frankel SH, et al. Performance evaluation of a pediatric viscous impeller pump for Fontan cavopulmonary assist. J Thorac Cardiovasc Surg. 2013;145:249-57.

\section{Discussion}

Dr Mark Rodefeld (Indianapolis, Ind). Dr Devaney, who is the original discussant for this article, was not able to make it because of weather problems in the United States, so I'll make a few comments.

Fontan circulatory support is really an evolving and still early-stage field. Obviously, the circulatory deficit in Fontan is the lack of a subpulmonary ventricle. So efforts to put a power source back into the circulation had been thought about, and it is a complicated flow situation with multiple directions of flow.

You've shown that a catheter with an inlet and outlet can have problems with recirculation, and therefore some type of barrier to recirculation is going to be required, and obviously using the umbrella is one way to do that. A balloon-type of occlusion is another potential way to do it.

You mentioned thrombogenicity as a concern, and, of course, that would be an immediate concern in the low-pressure circulation. Can you elaborate more in terms of what extent of clot that you saw in your studies. How much clot did you see?

Dr Wang. We have seen the small thrombosis under the umbrellas in 2 of 6 heparinized sheep in the 90-minute experiment. Because an obvious blood stagnant area exists under the umbrellas, we expect more thrombosis formation with longer-term use of the current device and less anticoagulation level. We have a new design to address this thrombosis problem. 